\title{
Pemberdayaan Ketahanan dan Keamanan Pangan Melalui Urban Farming di Masa Pandemi Covid-19
}

\author{
Rieska Maharani $^{1 \bowtie}$, Zainal Rusdi $^{2}$, Lynda Yunyver $^{3}$, Reza Mega Novalia $^{4}$, Adiva Salsabila ${ }^{5}$ \\ Akuntansi, Universitas Muhammadiyah Surabaya, Indonesia ${ }^{1,2,3,4,5}$ \\ E-mail: rieska.maharani@fe.um-surabaya.ac.id ${ }^{1}, \underline{\text { zainalrusdi9@gmail.com }}^{2}$, lyndayunyver2@gmail.com $^{3}$, \\ rezameganovalia@gmail.com ${ }^{4}, \underline{\text { adivasalsabila1904@gmail.com }}{ }^{5}$
}

\begin{abstract}
Abstrak
Kegiatan pengabdian ini dilakukan di RT 07 RW 03 Kecamatan Kendangsari, Kelurahan Tenggilis Mejoyo, Kota Surabaya dengan tujuan untuk meningkatkan keamanan dan ketahanan pangan di tengah pandemi Covid-19. Terutama di tengah pandemi Covid-19 masyarakat dituntut untuk terus berinovasi dengan keterbatasan yang ada, salah satunya adalah bertanam menggunakan teknik hidroponik guna mempertahankan keamanan pangan di tengah pandemi dengan memanfaaatkan serta mengoptimalisasi lahan kosong di tengah kota. Dalam hal ini, pemerintah juga berperan dalam memfasilitasi untuk akses pengembangan dengan bantuan hibah bernama Program Holistik Pembinaan dan Pemberdayaan Desa melalui Kementrian Pendidikan dan Kebudayaan yang dijembatani oleh tim penerima hibah yaitu Mahasiswa Program Studi Akuntansi Universitas Muhammadiyah Surabaya. Metode yang digunakan dalam kegiatan ini adalah penyuluhan, pengenalan dan praktik pelatihan hidroponik serta pembinaan bertanam secara hidroponik dari semai hingga panen, serta cara menjual sayur dan melakukan diversifikasi produk olahan dari sayur hidroponik. Hasil dari adanya program ini adalah secara tidak langsung akan terbentuk keamanan dan ketahanan pangan daerah sekitar serta bertambahnya pendapatan baru bagi masyarakat yang terdampak pandemi. Untuk terus memotivasi masyarakat dalam pengembangan kegiatan ini, kami akan mendampingi pemberdayaan dengan terus melakukan evaluasi dan monitoring secara berkelanjutan baik offline maupun online.

Kata kunci: hidroponik, Covid-19, diversifikasi produk, Kendangsari
\end{abstract}

\section{Abstract}

This service activity was carried out at RT 07 RW 03 Kendangsari Subdistrict, TenggilisMejoyo Village, Surabaya City to increase food security and security amid the Covid-19 pandemic. Especially during the Covid-19 pandemic, people are required to continue to innovate with existing limitations, one of which is planting using hydroponic techniques to maintain food security during a pandemic by utilizing and optimizing vacant land in the middle of the city. In this case, the government also plays a role in facilitating access to development with the help of a grant called the Holistic Program for Village Development and Empowerment through the Ministry of Education and Culture which is bridged by a team of grantees, namely Students of the Accounting Study Program, University of Muhammadiyah Surabaya. The methods used in this activity are counseling, introduction, and practice of hydroponic training as well as hydroponic cultivation coaching from seedling to harvesting, as well as how to sell vegetables and diversify processed products from hydroponic vegetables. The result of this program is that it will indirectly form food security and security in the surrounding area and increase new income for people affected by the pandemic. To continue to motivate the community in the development of this activity, we will assist empowerment by continuing to evaluate and monitor on an ongoing basis both offline and online.

Keywords: hydroponics, Covid-19, product diversification, Kendangsari

Copyright (c) 2021 Rieska Maharani, Zainal Rusdi, Lynda Yunyver, Reza Mega Novalia, Adiva Salsabila $\triangle$ Corresponding author

Address : Universitas Muhammadiyah Surabaya

Email : rieska.maharani@fe.um-surabaya.ac.id

DOI $\quad$ : https://doi.org/10.31004/abdidas.v2i5.443
ISSN 2721-9224 (Media Cetak)

ISSN 2721- 9216 (Media Online) 
1146 Pemberdayaan Ketahanan dan Keamanan Pangan Melalui Urban Farming Dimasa Pandemi Covid 19Rieska Maharani, Zainal Rusdi, Lynda Yunyver, Reza Mega Novalia, Adiva Salsabila

DOI: https://doi.org/10.31004/abdidas.v2i5.443

\section{PENDAHULUAN}

Ketahanan pangan menjadi topik utama yang ramai untuk diperbincangkan oleh berbagai unsur lapisan masyarakat, ramainya perbincangan ini tidak jauh dari adanya dampak akibat penyebaran Covid-19 yang semakin melebar penyebarannya. Di masa pandemi masyarakat harus bergulat dengan kesehatan dengan diimbangi oleh makanan bergizi. Direktur Jenderal Kesehatan Masyarakat Kementerian Kesehatan (Kemenkes), dr. Kirana Pritasari, MQIH, mengatakan pemenuhan gizi harus harus tetap diperhatikan. Hal tersebut dilakukan untuk menjaga imunitas agar terhindar dari infeksi penyakit termasuk Covid-19.

Selain itu konsumsi kebutuhan sehari-hari berdampak pada daya beli masyarakat, di mana pasokan pangan menjadi isu sentral yang perlu penanganannya sesegera mungkin. Kebutuhan pangan merupakan urusan dasar yang harus diperhatikan, ketersediaan dan aksesibilitas pangan yang terjangkau dari masyarakat perlu dijaga sehingga diusahakan dapat menciptakan ketahanan dan keamanan pangan yang stabil bagi masyarakat. (Heriawan dan Verselita, 2020).

Berdasarkan pernyataan yang dikeluarkan oleh Food Agriculture and Organization mengatakan bahwa pandemi merupakan krisis global yang sangat terdampak pada sektor pangan dan pertanian (Sofiyani dkk, 2021:342). Keadaan yang terjadi di tengah pandemi Covid-19 memaksakan masyarakat untuk cenderung merubah perilaku berkehidupan, terutama menyesuaikan dengan kebijakan pemerintah salah satunya untuk menerapkan karantina wilayah sesuai dengan peraturan wilayah masing-masing. Dimulai dari perubahan pola rantai pasokan pangan yang lebih menjamur pada pasar modern atau berbasis online, peningkatan fasilitas dari produksi hingga konsumsi. Perubahan pola ini memaksa manusia untuk lebih bisa beradaptasi oleh lingkungan sekitar salah satunya dengan kemandirian kebutuhan pangan.

Ketahanan pangan menutut Undang-Undang Nomor 18 tahun 2012 adalah terpenuhinya pangan bagi setiap negara sampai dengan perseorangan, yang tercermin dan tersedianya pangan yang cukup, baik jumlah maupun mutunya, aman, beragam, bergizi, merata dan terjangkau serta tidak bertentangan dengan agama, keyakinan dan budaya masyarakat, untuk dapat hidup sehat, aktif, dan produktif secara berkelanjutan. Sedangkan keamanan pangan menurut BPOM adalah kondisi dan upaya yang diperlukan untuk mencegah pangan dari kemungkinan tiga cemaran yaitu cemaran biologis, kimia dan benda lain yang dapat menganggu, merugikan dan membahayakan kesehatan manusisa serta tidak bertentangan dengan agama, keyakinan dan budaya masyarakat sehingga aman untuk dikonsumsi. (Sofyani dkk, 2021:342).

Selain masalah pandemi COVID-19 yang terus meradang, manusia juga dihadapi oleh lahan yang semakin sempit. Menurut Badan Pusat Statistik menyebutkan bahwa luas lahan baku sawah di Indonesia terus mengalami penurunan, luas lahan pada tahun 2018 hanya tinggal 7,1 juta hektare. Tentunya dengan data dan angka ini menurun jika dibandingkan dengan data yang dirilis pada tahun 2017 yang di mana memiliki luas 
1147 Pemberdayaan Ketahanan dan Keamanan Pangan Melalui Urban Farming Dimasa Pandemi Covid 19Rieska Maharani, Zainal Rusdi, Lynda Yunyver, Reza Mega Novalia, Adiva Salsabila

DOI: https://doi.org/10.31004/abdidas.v2i5.443

lahan sebesar 7,75 juta hektar. Alih fungsi lahan atau konversi lahan merupakan penyebab terjadinya penurunan luas lahan di Indonesia. Masalah tersebut juga muncul terutama di daerah perkotaan yang pada umumnya penduduk yang tinggal di perkotaan tidak memiliki lahan yang cukup untuk bertanam secara konvensional sehingga menambah permasalahan untuk ketahanan pangan.

Berdasarkan permasalahan yang terjadi muncullah solusi atas masalah tersebut berkenaan dengan adanya Program Holistik Pembinaan dan Pemberdaaan Desa dari Kemendikbud yang mengusung tema urban farming menggunakan teknik hidroponik. Teknik hidroponik merupakan sistem budidaya yang mengandalkan air dengan larutan nutrisi tanpa menggunakan tanah. Dapat diketahui bahwa teknologi dengan sistem tanam hidroponik ini memiliki banyak keunggulan dan kemudahan dalam melakukan budidaya jika dibandingkan dengan teknik bertanam konvensional, ada beberapa keunggulan dari sistem penanaman dengan model hidroponik antara lain fleksibel, ramah lingkungan, produk luaran yang higienis, masa tanam lebih cepat kualitas tanaman terjaga dan dapat menghemat tenaga kerja (Anika dan Putra, 2020:368).

Maka dari itu hidroponik dinilai efektif dalam permasalahan kurangnya lahan dan menjamin keamanan dan ketahanan pangan karena tanaman ditanam sendiri. Latar belakang utama dalam pengabdian ini adalah guna memberdayakan masyarakat yang terdampak pemutusan hubungan kerja dengan terget sasaran semua lapisan masyarakat, pada pengabdian ini juga berfokus pada bimbingan kepada masyarakat untuk bercocok tanam menggunakan teknik hidroponik guna memenuhi kebutuhan pangan harian untuk meningkatkan ketahanan dan keamanan pangan di tengah pandemi Covid-19 agar masyarakat terdampak bisa mandiri dalam memenuhi kebutuhannya. Tidak cukup sampai di sana, pengabdian ini juga menyertakan solusi atas permasalahan yang nantinya muncul setelah sayuran berhasil ditanam tetapi tidak habis terjual yaitu dengan adanya diversifikasi produk berupa produk olahan. Hal ini sesuai oleh penelitian yang dilakukan oleh (Mochklas dkk, 2021:87) yang menyatakan bahwa pengabdian merupakan kunci keberhasilan yang di mana dari adanya pemberdayaan masyarakat ini diharapkan dapat terciptanya kemandirian pada masyarakat. Pengabdian ini dilakukan di Kelurahan Kendangsari RW 03 Kecamatan Tenggilis Mejoyo, Kota Surabaya.

\section{METODE}

Pengabdian pada masyarakat ini dilakukan pada bulan Agustus hingga Desember 2020. Dengan menggunakan metode pendekatan penyuluhan diikuti dengan pelatihan kelompok. Tujuan dari pengabdian ini guna menciptakan ketahanan dan keamanan pangan pada masyarakat sehingga masyarakat diminta untuk mandiri dalam memenuhi kebutuhan, di samping itu juga dapat menggali potensi dan menjadi solusi bagi masyarakat terdampak hubungan pemutusan kerja untuk dapat mengusahakan bercocok tanam hingga dapat dijual sehingga menciptakan pendapatan baru bagi masyarakat. 
1148 Pemberdayaan Ketahanan dan Keamanan Pangan Melalui Urban Farming Dimasa Pandemi Covid 19Rieska Maharani, Zainal Rusdi, Lynda Yunyver, Reza Mega Novalia, Adiva Salsabila

DOI: https://doi.org/10.31004/abdidas.v2i5.443

Kegiatan pengabdian yang dilaksanakan tentunya melibatkan mahasiwa mulai dari proses pelatihan hidroponik dari awal hingga panen dan juga pendampingan mengolah produk olahan atau diversifikasi produk. Secara keseluruhan program tim pengabdi selalu bekerja sama dalam perencanaan mulai dari persiapan timeline, skema turun lapangan, pemecahan masalah dan pengimplementasian ide ke lapangan.

Pelaksanaan pengabdian ini dibagi menjadi tahapan skema untuk dapat dikatakan selesai yaitu perkenalan penyuluhan program, pemahaman konsep pelatihan hidroponik, pembinaan cara penjualan sayur dan menentukan harga jual, pelatihan pengolahan produk diversifikasi, monitoring serta evaluasi program pengabdian pada masyarakat :

- Pengenalan penyuluhan program, mencakup perkenalan dan edukasi mengenai tema dari ketahanan dan keamanan pangan, memaparkan permasalahan yang terjadi terutama di tengah pandemi COVID-19 hingga muncul solusi atas permasalahan yaitu hidroponik.

- Pemahaman konsep pelatihan hidroponik, pada kegiatan ini tim pengabdian berfokus pada cara dasar bertanam menggunakan hidroponik, mulai dari pembibitan, teknik semai pada media tanam, cara perawatan pemberian pupuk cair, cara penanggulangan hama, perlakuan pindah tanam hingga panen, penentuan teknik penjadwalan continue agar produksi sayur terus dapat dilakukan.

- Pembinaan cara penjualan sayur dan menentukan harga jual, kegiatan ini bertujuan untuk memberikan edukasi kepada masyarakat cara memasarkan produk dan memberikan pelatihan dasar cara menghitung untuk menentukan harga pokok produk perunit sayur dan berguna untuk penentuan harga jual yang sudah ditambahkan dengan keuntungan yang diinginkan.

- Pelatihan pengolahan produk diversifikasi, pelatihan ini bertujuan agar tidak ada sayur yang terbuang, bahan utama dari olahan ini adalah sayur yang tidak lolos quality qontrol atau sayur sisa tidak habis dijual agar dipergunakan kembali untuk dijadikan olahan sehingga menghasilkan nilai tambah pada produk hidroponik.

- Monitoring serta evaluasi program pengabdian pada masyarakat, pada tahap ini dilakukan pemantauan rutin oleh tim pengabdian dengan berkunjung ke lokasi tempat berdirinya Green House dan juga dilakukan secara online melalui media whatsapp, evaluasi rutin dilakukan untuk upgrade fasilitas yang ada di Green House sehingga tempat pengabdian menjadi lebih berkembang dengan diiringi penambahan nilai ekonomis.

\section{HASIL DAN PEMBAHASAN}

Upaya peningkatan ketahanan dan keamanan pangan di Kelurahan Kendangsari dimulai dengan perizinan melalui Bakesbangpol Kota Surabaya, Kelurahan dan Kecamatan lalu RW dan sampailah pada sosialiasasi penyuluhan kepada seluruh ketua RT pada RW 03, penyuluhan dan sosialisasi ini bertujuan untuk berdiskusi mengenai pemaparan program sekaligus meminta izin kepada perangkat desa. Diskusi dilakukan 
1149 Pemberdayaan Ketahanan dan Keamanan Pangan Melalui Urban Farming Dimasa Pandemi Covid 19Rieska Maharani, Zainal Rusdi, Lynda Yunyver, Reza Mega Novalia, Adiva Salsabila

DOI: https://doi.org/10.31004/abdidas.v2i5.443

untuk menentukan tempat yang cocok untuk dijadikan wilayah pemasangan instalasi pada setiap RT. Permasalahan yang dialami tim pengabdian di lapangan adalah kurangnya kesadaran masyarakat terhadap ketahanan dan keamanan pangan secara mandiri.

\section{Persiapan dan Koordinasi Penempatan \\ Kegiatan}

Persiapan dan koordinasi di lapangan diawali dengan melakukan diskusi kepada ketua RW mengenai RT yang berpotensi untuk dikembangkan, mengunjungi setiap RT untuk menentukan lokasi pemasangan instalasi. Dari semua diskusi pada setiap RT tim pengabdian membicarakan suatu lapangan kosong yang berpotensi untuk dibangun sebuah Green House yang bertujuan sebagai pusat dari budidaya hidroponik pada Kawasan Kendangsari, dengan mempertimbangkan berbagai aspek seperti perizinan lahan, perangkat desa, jarak lokasi dengan pemukiman warga, sinar matahari, struktur tanah, ketersediaan warga sekitar, sehingga tim pengabdian dan atas izin perangkat desa memutuskan untuk membangun Green House pada suatu lahan kosong dengan ukuran Green House $6 \mathrm{~m}$ x $12 \mathrm{~m}$. Untuk menjangkau warga RT lain, tim pengabdian juga membangun instalasi pada setiap RT yang bersedia untuk digunakan wilayah pengabdian diantaranya RT 01, RT 04, RT 05, RT 06, RT 07, dan RT 09, kebetulan Green House berada di RT 07 yang memiliki potensi sumber daya manusia yang sangat memadai.
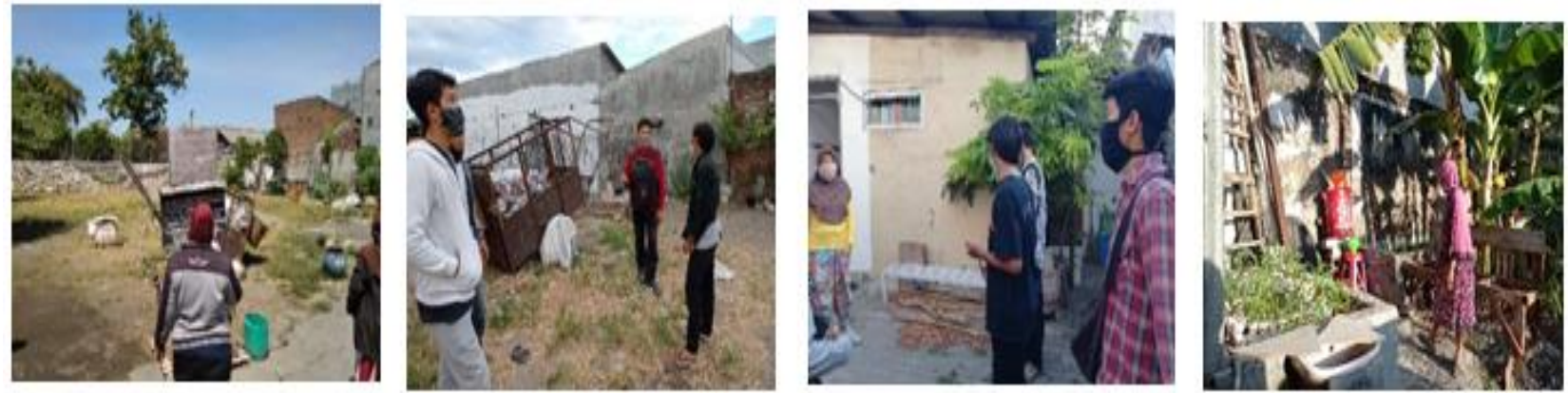

Gambar 1. Diskusi Persiapan dan Koordinasi Penempatan Kegiatan Bersama Warga Masyarakat

\section{Pelaksanaan Kegiatan Pembuatan Instalasi}

Tahapan pembuatan instalasi dimulai dengan pembuatan instalasi individu pada setiap RT dan melakukan pengukuran lokasi yang akan dipasangi instalasi pada setiap RT untuk menentukan besaran instalasi yang akan dibuat, lalu pembelian alat yang dibutuhkan seperti pipa dengan beragam ukuran, knee, tee, dop, overshok, netpot, bak kontainer, mesin pompa, dan sebagainya. Proses pembuatan satu instalasi individu RT memakan waktu sekitar 1 minggu dengan hari pembuatan pada Rabu, Jumat, Sabtu dan Minggu. Pembuatan ini cukup memakan waktu sebab tim pengabdian merakit sendiri secara keseluruhan tanpa dibantu oleh pihak yang ahli, lalu di samping itu pembuatan kuda-kuda pada Green House juga tetap berjalan. Pembuatan Green House yang membutuhkan waktu sangat 
1150 Pemberdayaan Ketahanan dan Keamanan Pangan Melalui Urban Farming Dimasa Pandemi Covid 19Rieska Maharani, Zainal Rusdi, Lynda Yunyver, Reza Mega Novalia, Adiva Salsabila

DOI: https://doi.org/10.31004/abdidas.v2i5.443

lama untuk dapat berdiri butuh waktu 3 bulan secara keseluruhan untuk dapat membangunnya, tim pengabdian dibantu oleh warga dalam pembuatan kerangka Green House dengan sisanya dikerjakan sendiri oleh tim pengabdian tanpa bantuan ahli. Dalam seminggu pengerjaan dilakukan dalam 4 hari terkadang 5 hari untuk mengejar target timeline.

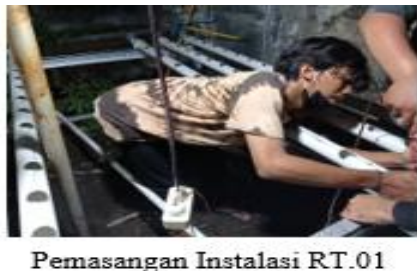

(Sistem NFT)

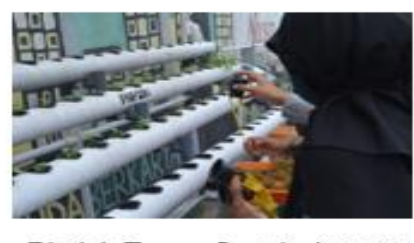

Pindah Tanam Instalasi RT.09 (Sistem DFT)

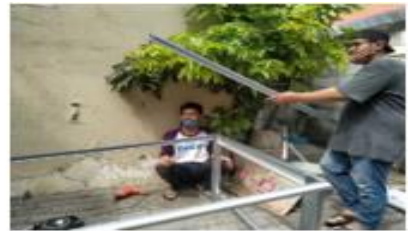

Pemasangan Instalasi RT.05 (Sistem NFT)

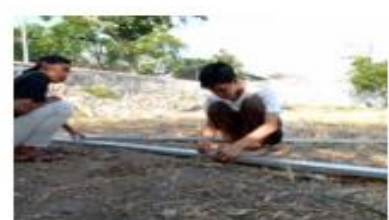

Proses Pembuat Greenhouse

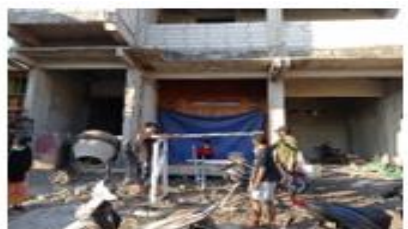

Pemasangan Instalasi RT.06 (Sistem NFT)

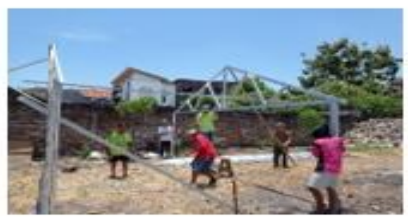

Pemasangan Pondasi GH Bersama Warga

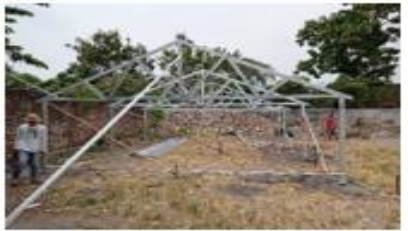

Kerangka Greenhouse

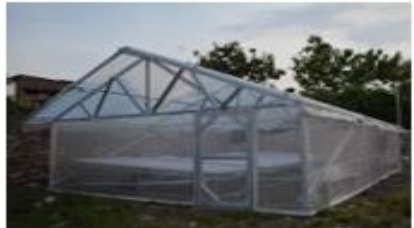

Greenhouse (Sistem NFT \& DFT)

Gambar 2. Instalasi Tiap RT dan Green House

\section{Pelatihan Hidroponik}

Pelatihan hidroponik diberikan kepada masyarakat sasaran mulai dari cara penyemaian dan perilaku semai pada setiap bibit semua jenis sayur, cara pemberian air, lamanya masa semai, cara pemindahan tanam, pemberian $A B$ mix sesuai dengan jenis sayur, pengukuran $\mathrm{pH}$ dan TDS meter, lamanya masa tanam, cara panen, cara membasmi hama dan seluruh rangkaian yang berkenaan dengan proses penanaman. Pelatihan hidroponik ini juga menjelaskan waktu-waktu yang seharusnya dianjurkan contohnya panen dan semai baik dilakukan pada sore hari. Pelatihan hidroponik dilakukan ketika instalasi individu RT siap untuk digunakan dengan target sasaran warga RT tersebut, berbeda dengan Green House yang memiliki kelompok binaan yang bernama Bejoasri terdiri dari beberapa warga dari perwakilan setiap RT pada RW 03 Kendangsari. Kelompok binaan Green House juga memiliki divisi masing-masing sesuai dengan kebutuhan diantaranya marketing, penanaman, dan logistik. 
1151 Pemberdayaan Ketahanan dan Keamanan Pangan Melalui Urban Farming Dimasa Pandemi Covid 19Rieska Maharani, Zainal Rusdi, Lynda Yunyver, Reza Mega Novalia, Adiva Salsabila

DOI: https://doi.org/10.31004/abdidas.v2i5.443

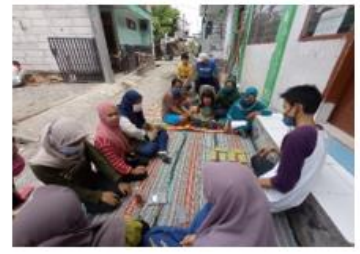

Pelatihan Hidroponik Tiap RT

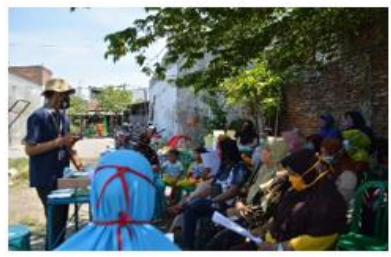

Pelatihan Hidroponik Kelompok Binaan Greenhouse

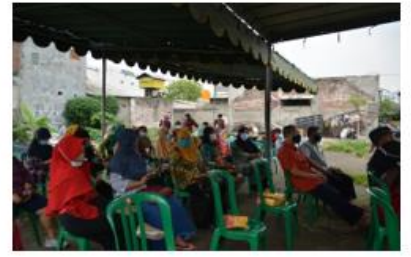

Pelatihan Hidroponik bagi Warga RW.03

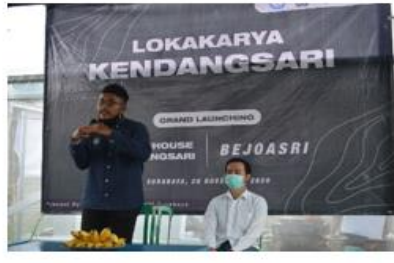

Pelatihan Hidroponik bersama DKPP Kota Surabaya

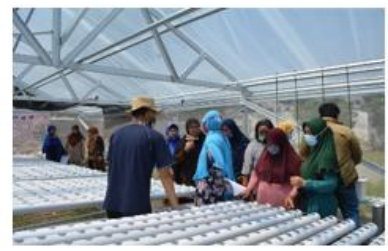

Pelatihan Hidroponik Langsung

\section{Gambar 3. Pelatihan Hidroponik dan Kelompok Binaan}

\section{Pelatihan Diversifikasi Produk Olahan}

Pelatihan diversifikasi produk bertujuan untuk memberdayakan ibu-ibu rumah tangga untuk dapat menghasilkan penghasilan tambahan. Produk dibuat dari hasil sisa sayur hidroponik pada Green
House yang tidak habis terjual atau tidak lolos quality control untuk dipasarkan. Sayuran yang diolah dapat menghasilkan diversifikasi berupa pempek kangkung dan cireng kangkung.
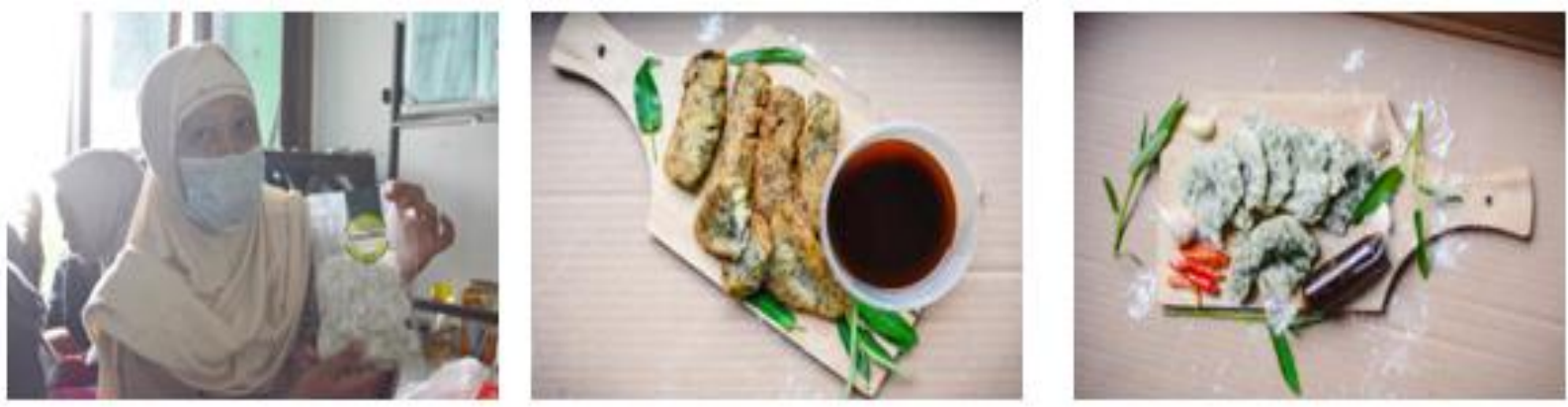

\section{Gambar 4. Pelatihan Diversifikasi Produk}

\section{Pelatihan Pemasaran dan Perhitungan}

\section{Harga Jual}

Produk sayuran dijual kepada warga sekitar sedangkan produk diversifikasi dijual secara online ke seluruh Surabaya. Agar produk sayur dan produk olahan dapat meningkatkan penjualan masyarakat diberikan pelatihan pemasaran dengan menggunakan platfrom digital atau dapat tembus ke swalayan atau restoran. Dalam pemasarannya produk harus dihitung terlebih dahulu berapa biaya yang dikeluarkan baik sayuran maupun produk olahan, warga dilatih untuk dapat menghitung sendiri besaran biaya yang dikeluarkan per unitnya ditambah dengan persentase 
1152 Pemberdayaan Ketahanan dan Keamanan Pangan Melalui Urban Farming Dimasa Pandemi Covid 19Rieska Maharani, Zainal Rusdi, Lynda Yunyver, Reza Mega Novalia, Adiva Salsabila DOI: https://doi.org/10.31004/abdidas.v2i5.443

keuntungan yang diinginkan untuk kemudian dapat menetapkan harga jual.
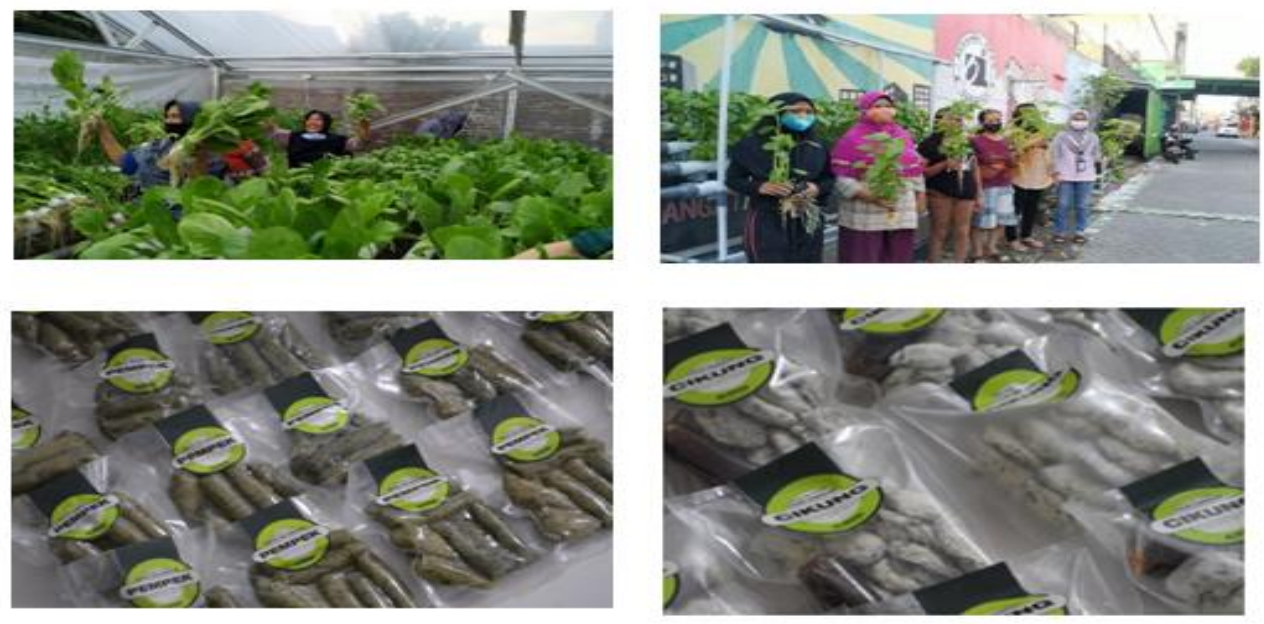

Gambar 5. Hasil Panen dan Diversifikasi Olahan Sayur Monitoring Kegiatan

Monitoring kegiatan dan evaluasi pasca kegiatan pengabdian masyarkat Kendangsari dilakukan secara berkala melalui online media

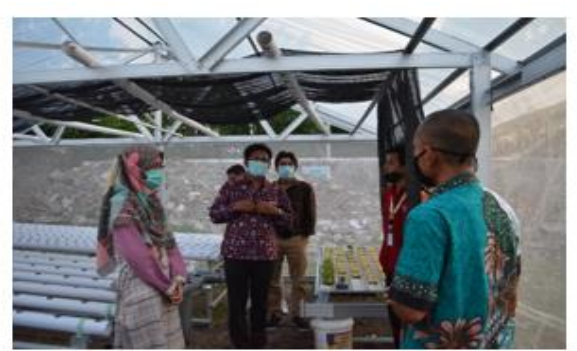

Monitoring Kegiatan Bersama Dosen Pembimbing

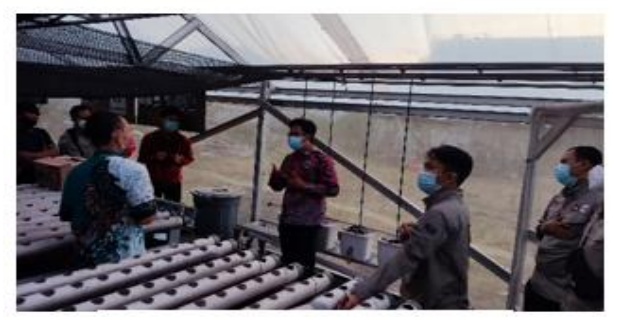

Monitoring Kegiatan Bersama

Pihak Kampus
WhatsApp dan terkadang peninjauan langsung ke tempat pengabdian untuk melihat perkembangan lapangan.

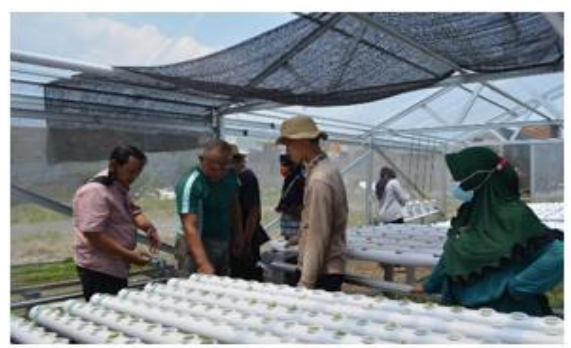

Monitoring Kegiatan Bersama Ketua RW

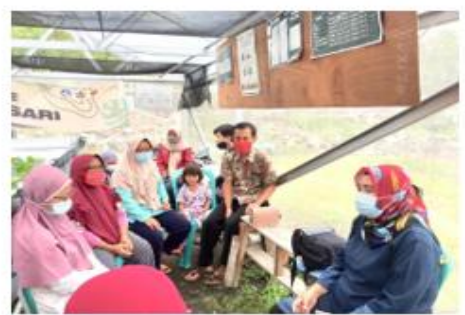

Monitoring Kegiatan Bersama Pihak Kecamatan

Gambar 6. Instalasi Tiap RT dan Green House

\section{SIMPULAN}

Pengabdian masyarakat ini merupakan upaya pemerintah dan dijembatani oleh Perguruan
Tinggi melalui mahasiswa untuk dapat mengimplementasikan ide serta dalam mengembangkan potensi desa. Keberhasilan 
1153 Pemberdayaan Ketahanan dan Keamanan Pangan Melalui Urban Farming Dimasa Pandemi Covid 19Rieska Maharani, Zainal Rusdi, Lynda Yunyver, Reza Mega Novalia, Adiva Salsabila

DOI: https://doi.org/10.31004/abdidas.v2i5.443

program ini dapat dilihat dari pencapaian di antaranya dalam kurun waktu hampir 10 bulan tahun green house sudah berhasil melakukan 4 kali masa panen dan para kelompok binaan berhasil untuk menambah income pada green house dengan penambahan kolam ikan lele pada bawah instalasi, penambahan ini didapatkan dari keuntungan menjual sayur hidroponik untuk kemudian membudidayakan lele. Untuk kelompok binaan produk olahan sudah berhasil memasarkan produk ke seluruh Kota Surabaya dengan total omset mencapai Rp. 5.000.000.

\section{UCAPAN TERIMA KASIH}

Kami sampaikan banyak terima kasih kepada Kepala BAKAI Universitas Muhammadiyah Surabaya yang memberikan dukungan kegiatan ini, dan kepada Mahasiswa Universitas Muhammadiyah Surabaya yang terlibat pengabdian di Kecamatan Kendangsari Kelurahan Tenggilis Mejoyo Kota Surabaya yakni Zainul Rusdi, Lynda Yunyver, Reza Mega Novalia, Adiva Salsabila, Kurnia Anggrahiny, Margi Susilowati, Dina Nur Safitri, Junaidi Syahrianto, Aulia Nurisa Salsabilla, Malik Fadjar Alfarisi, Ryan Yuda Pratama, Junio Edo Trimadhani, Lidia Choirunnisa, Ristu Alfira Nurfajri, Lailatus Sa'diyah, Farida Hanum.

\section{DAFTAR PUSTAKA}

Anika, N., Putra, E. P. D. (Desember 2020). Analisi Pendapatan Usahatani Sayuran Hidroponik Dengan Sistem Deep Flow Technique (DFT). Jurnal Teknik Pertanian Lampung, Vol. 9 No. 4, h. 396.
Mochklas, M., Hidajat, S., Mauliddah, N. (Januari 2021). Pemberdayaan Potensi Desa Kebon Raya Paciran Lamongan di Era Ner Normal. Jurnal Abdidas, Vol. 2 No. 1, h. 87.

Mochklas, M., Rusmawati, Z., Santoso, A., \& Jannah, R. (2019). Pendampingan kampung pendidikan kampung'e arek Suroboyo (KP KAS) RW 03 Kelurahan Ketintang Surabay. Jurnal Komunitas: Jurnal Pengabdian kepada Masyarakat, 2(1), 51-59.

Sofyani, G. V., Putri, E. B. P., Fajrin, L., Murtasiyah, E. I., Thoyyib, Z. B. (Januari 2021). Pengingkatan Ketahanan Pangan dan Keamanan Pangan Dimasa Pandemi COVID19 Dengan Penanaman Hidroponik di Dukunanyar Gresik. Jurnal Pengabdian Kepada Masyarakat, Vol. 2 No. 1, h.342.

Badan Pusat Statistik Jakarta Pusat. (2021). Pendataan Produksi Tanaman Sayuran tahun 2017-2019. Jakarta Pusat: Badan Pusat Statistik. https://www.bps.go.id/site/pilihdata

Undang-Undang Nomor 18 tahun 2012 tentang Pangan 